\title{
Regional Anaesthesia versus General Anaesthesia in Endovascular Aneurysm Repair: The Surgical Nursing Interventions
}

\author{
T. Fotis ${ }^{1}$, A. Mitsos ${ }^{2}$, T. Perdikides ${ }^{1}$, E. Lambrinou ${ }^{3}$, E. Konstantinou ${ }^{4}$ \\ ${ }^{1}$ Vascular Surgical Department, 251 Hellenic Airforce Hospital, Athens, Greece; ${ }^{2}$ National and \\ Kapodistrian University of Athens, Major, Neurosurgeon, 401 Army Hospital, Athens, Greece; \\ ${ }^{3}$ TEPAK, Faculty of Nursing, Nicosia, Cyprus; ${ }^{4}$ School of Nursing, Athens University, Athens, Greece
}

\section{ABSTRACT}

Background: Minimally invasive surgical techniques are a revolutionary and innovative approach to the practice of surgery. Endovascular aneurysm repair (EVAR) may offer a number of significant advantages in comparison with conventional open surgical repair.

Aim: The purpose of this study was to compare regional anaesthesia (RA) and general anaesthesia (GA) in EVAR, and to describe the surgical nursing interventions.

Methods: This included a retrospective analysis of 160 consecutive patients (age 55 to 96 years) who underwent EVAR under: epidural anaesthesia (EDA $=60$ patients), combined spinal and epidural anaesthesia (Combined $=40$ patients) and $\mathrm{GA}=60$ patients.

Results: Results were successful in all patients and no mortality was noticed. Among the GA group, 11 patients needed ICU support while only 5 from the other 2 groups. Furthermore, a statistically significant difference regarding median hospital stay was also noticed in favour of the regional group.

Conclusion: In conclusion, RA is a safe and effective anaesthetic method for endovascular repair of abdominal aneurysms, offering several

Correspondence to: T. Fotis, RN, BSc, MSc, PhD Candidate, P.O. Box 1323, 19009 Pikermi Attikis, Greece. Tel: 00302106035260, Fax: 00302106035260, E-mail: thfotis@nurs.uoa.gr advantages including simplicity, haemodynamic stability, less need for ICU management and reduced hospital stay. The anaesthetic nurse can play a major role in the management of this anaesthesia throughout the procedure.

Key words: Abdominal aortic aneurysm (AAA); endovascular aneurysm repair (EVAR); general anaesthesia; regional anaesthesia; surgical nursing

\section{INTRODUCTION}

Minimally invasive techniques are a revolutionary and innovative approach to the practice of surgery. These techniques are being used in an increasing number of patients with cardiovascular conditions, which can offer a number of significant advantages [Bettex et al, 2001]. The surgical nurse should be alert in order to adapt to the new approach in anaesthesia management for these procedures.

\section{MATERIALS AND METHODS}

Between 2002 and 2008, 160 patients (152 men, $76.9 \%$; and 8 women, $4 \%$; average age 72.9 years and range 55 to 96 years), underwent endovascular aneurysm repair (EVAR). All patients signed the consent inform and the study was approved by the hospital's ethics committee. Patients' data was retrospectively recorded for the preoperative, perioperative 
Table 1. Patient characteristics

\begin{tabular}{|c|c|c|c|}
\hline & $\begin{array}{l}\text { GA } \\
n=60\end{array}$ & $\begin{array}{l}\text { EDA } \\
n=60\end{array}$ & $\begin{array}{l}\text { Combined } \\
n=40\end{array}$ \\
\hline \multicolumn{4}{|l|}{ Gender } \\
\hline Males & $95 \%(57)$ & $95.1 \%(58)$ & $95 \%(37)$ \\
\hline Females & $5 \%(3)$ & $4.9 \%(3)$ & $5 \%(2)$ \\
\hline Age $(y r)$ & $\begin{array}{l}73.5 \pm 4.7 \\
\min =65, \max =80\end{array}$ & $\begin{array}{l}74 \pm 6.4 \\
\min =58, \max =84\end{array}$ & $\begin{array}{l}74 \pm 10.2 \\
\min =55, \max =89\end{array}$ \\
\hline \multicolumn{4}{|l|}{ ASA } \\
\hline $\mathrm{I}$ & $73.9 \%$ & $53.7 \%$ & $55.6 \%$ \\
\hline II & $17.4 \%$ & $26.8 \%$ & $29.6 \%$ \\
\hline III & $4.3 \%$ & $17.1 \%$ & $11.1 \%$ \\
\hline IV & $4.3 \%$ & $2.4 \%$ & $3.7 \%$ \\
\hline AAA diameter $(\mathrm{mm})$ & $\begin{array}{l}52 \pm 6.2 \\
\min =45, \max =66\end{array}$ & $\begin{array}{l}53 \pm 6.7 \\
\min =45, \max =70\end{array}$ & $\begin{array}{l}54.5 \pm 8.5 \\
\min =41, \max =67\end{array}$ \\
\hline
\end{tabular}

$\mathrm{GA}=$ general anaesthesia; $\mathrm{EDA}=$ epidural anaesthesia; Combined $=$ combined spinal and epidural anaesthesia; ASA $=$ American Society of Anesthesiologists, physical status classification; AAA = abdominal aortic aneurysm.

and postoperative periods (Table 1). Descriptive statistics, including the mean, median, ranges and standard deviations were calculated for all the continuous baseline demographic and laboratory characteristics. Operative and postoperative variables were compared using the $\chi^{2}$-test. Group differences were evaluated by Mann-Whitney test. Differences were considered significant at $\mathrm{p} \leqslant 0.05$.

\section{RESULTS}

EVAR results were successful in all patients and no mortality was noticed.

There were substantial differences in favour of anaesthesia techniques with regard to the duration of hospital stay and ICU care. The regional anaesthesia (RA) group was shown to be significantly more successful in terms of outcome than the general anaesthesia (GA) group, since from the RA group and the combined spinal and epidural anaesthesia (Combined) group, only 5 patients needed ICU care in comparison with 11 patients of the GA group $(\mathrm{p}=0.00$ and $\mathrm{p}=0.01$, respectively) (see Figs 1 and 2). Furthermore, a statistically significant difference regarding median hospital stay was also noticed, in favour of the regional group $(\mathrm{p}=0.01)$ (see Fig. 3).

\section{DISCUSSION}

The main finding of this study was that RA is a safe and effective technique for EVAR in most patients. It has significant advantages over GA because of the

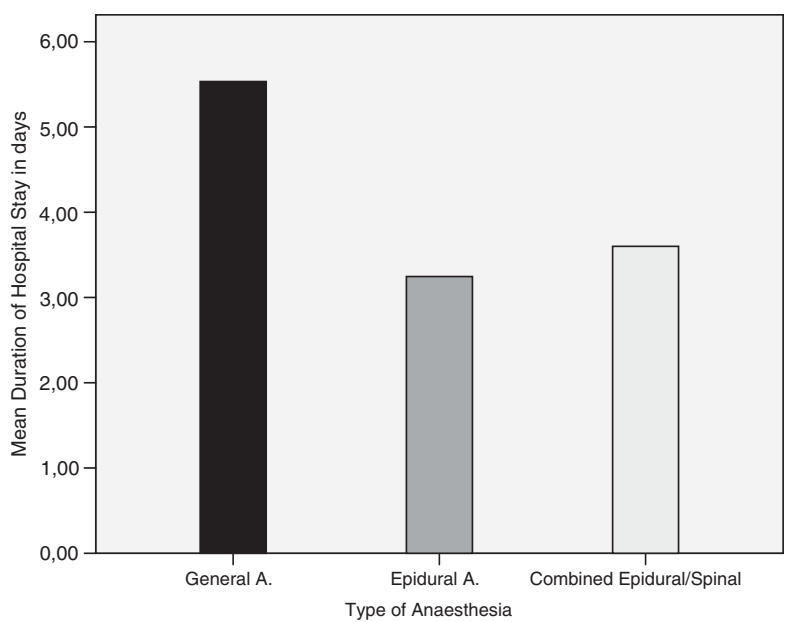

Figure 1. Comparison of the type of anaesthesia with the mean duration of hospital stay in days.

haemodynamic stability it provides, and the subsequent reduced need for ICU stay and shorter hospitalisation as previously described [Parra et al, 2005].

There are few publications which have studied the effect of the anaesthesia technique for EVAR, but all have concluded that RA had an advantage in reducing hospital and ICU stay and that general anaesthesia was an independent risk factor for perioperative complications after EVAR [Cao et al, 1999; Walschot et al, 2002; Ruppert, 2006]. The authors recognise that co-morbidities are common for patients with any form of vascular disease due to the end-product of generalised disease. Therefore, it is prudent to assume that all patients for endovascular surgery have coronary and 


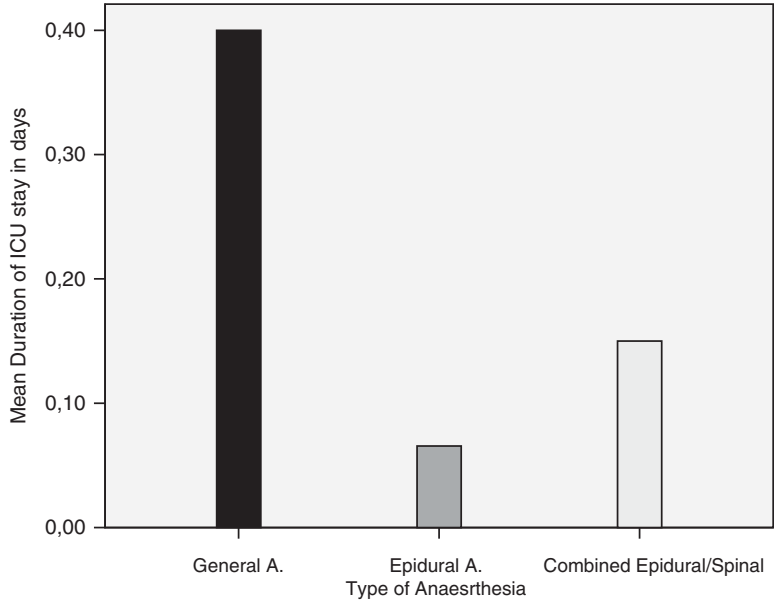

Figure 2. Comparison of the type of anaesthesia with the mean duration of ICU care in days.

cerebral vascular disease, and accordingly to manage them with this in mind when planning care [Hertzer et al, 1984; Clark and Stanley, 1994]. With this new surgical technique, the cardiac strain is reduced and in combination with the lighter anaesthesia the overall results are improved. The limitations of our study include the fact that the results are from a single surgical centre and therefore do not represent the general situation.

\section{SURGICAL NURSING INTERVENTIONS}

Nurses of the anaesthesia department are called to play a key role in these innovative surgical techniques. The patient is not intubated, but is still undergoing a serious procedure. The role of the anaesthetic nurse in EVAR surgery has to adapt accordingly, but should always include the following procedures. The nurse should meet the patient before the procedure and crosscheck the personal data, checking the preoperative laboratory results and carefully studying the past medical history. Along with the anaesthetist, the nurse should be in a position to inform the patient about the anaesthesiology procedures and answer questions. Throughout the preoperative phase, it is still vital that observations are recorded [Kozon et al, 1998; Sullivan, 2000; Ramage et al, 2001; Latessa, 2002; Hall, 2003]. During the procedure, monitoring should include ECG, pulse oximetry, $\mathrm{PCO}_{2}$, temperature and intra-arterial pressure. It is also critical to monitor urine flow, since contrast is used perioperatively which may have an

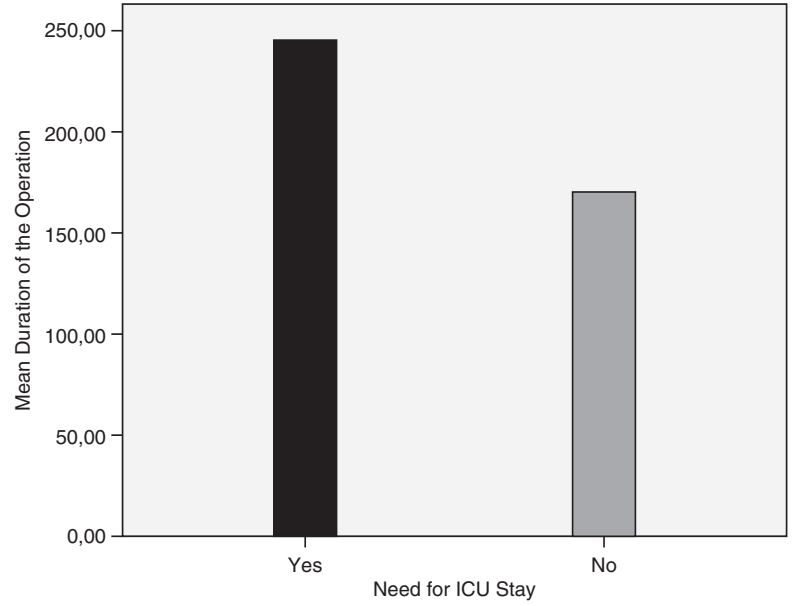

Figure 3. Comparison of operating time (in minutes) with the need of ICU care.

impact on kidney function [Baker, 2002]. Blood loss is usually not a major issue, but there will be a steady loss through the valved access catheters when there are catheters or wires in the vessels, compromising valve closure. In addition to intra-operative heparinisation, there is a common surgical usage of low-molecularweight heparin (LMWH) for prophylaxis against deepvein thrombosis and pulmonary embolisation. This use of epidural with LMWH has attracted much attention due to epidural haematoma in patients on $\mathrm{LMWH}$ [Horlocker and Wedel, 1998].

The anaesthesia nurse should never forget that the patient is in their senses throughout the procedure and must advocate privacy and safety at all times [Sullivan, 2000].

Due to the reduction of perioperative stress experienced by the patient, there is no need for a planned ICU stay, therefore the patient is transferred to the Postanaesthesia Care Unit (PACU) postoperatively. The patient stays at the PACU until he/she is stabilised. It is vital that PACU staff record neurovascular observations in these patients [Baker, 2002].

\section{CONCLUSIONS}

Endovascular technology continues to improve. It is very likely that more of these endovascular procedures will be performed under RA in favour of its better postoperative results for the patient. Since anaesthesia will continue to adapt to these changes, so will the demands of patients and surgeons/radiologists so as not to compromise the safety or comfort of the patient. 


\section{REFERENCES}

Baker B. Anesthesia and endovascular surgery. Best Practice and Research. Clinical Anesthesiology 2002; 16(1): 95-113.

Bettex DA, Lachat M, Pfammatter T, Schmidlin D. To compare general, epidural and local anaesthesia for endovascular aneurysm repair (EVAR). European Journal of Vascular and Endovascular Surgery 2001; 21(2): 179-184.

Cao P, Zannetti S, Parlani G, Verzini F, Caporali S, Spaccatini A. Epidural anesthesia reduces length of hospitalization after endoluminal abdominal aortic aneurysm repair. Journal of Vascular Surgery 1999; 30(4): 651-657.

Clark N, Stanley T. Anesthesia for vascular surgery In: Miller R. (ed.) Anesthesia (4th edn). New York: Churchill Livingstone, 1994, 1851-1895.

Hall S. Endovascular repair of abdominal aortic aneurysms. AORN Journal 2003; 77(3): 631-642.
Hertzer N, Beven E, Young J. Coronary artery disease in peripheral vascular patients: a classification of 1000 angiograms and results of surgical management. Annals of Surgery 1984; 199: 223-233.

Horlocker T, Wedel D. Neuraxial block and low-molecular-weight heparin: balancing perioperative analgesia and thromboprophylaxis. Regional Anesthesia Pain Medicine 1998; 23(2): 164-177.

Kozon V, Fortner N, Holzenbein T. An empirical study of nursing in patients undergoing two different procedures for abdominal aortic aneurysm repair. Journal of Vascular Nursing 1998; 16(1): 1-5.

Latessa V. Endovascular stent-graft repair of descending thoracic aortic aneurysms: the nursing implications for care. Journal of Vascular Nursing 2002; 20(3): 86-93.

Parra J, Crabtree T, McLafferty R, Ayerdi J, Gruneiro L, Ramsey D.
Anesthesia technique and outcomes of endovascular aneurysm repair. Annals of Vascular Surgery 2005; 19(3): 123-129.

Ramage D, Lovell M, Derose G. Establishing an endovascular abdominal aortic program - decisions, decisions, decisions: The London Health Sciences Centre experience. Journal of Vascular Nursing 2001; 19(1): 10-13.

Ruppert V. Influence of anesthesia type on outcome after endovascular aortic aneurysm repair: an analysis based on EUROSTAR data. Journal of Vascular Surgery 2006; 44(6): 16-21.

Sullivan E. Endovascular abdominal aortic aneurysm repair. Journal of Perianesthesia Nursing 2000; 15(4): 256-257.

Walschot L, Laheij R, Verbeek A. Outcome after endovascular abdominal aortic aneurysm repair: a metaanalysis. Journal of Endovascular Therapy 2002; 9: 82-89. 